\title{
Does treatment adherence correlates with health related quality of life? findings from a cross sectional study
}

\author{
Fahad Saleem ${ }^{1 *}$, Mohamed Azmi Hassali ${ }^{2}$, Asrul Akmal Shafie ${ }^{2}$, George A Awad $^{3}$, Muhammad Atif ${ }^{4}$, Noman ul Haq ${ }^{1}$, \\ Hisham Aljadhey ${ }^{5}$ and Maryam Farooqui ${ }^{6}$
}

\begin{abstract}
Background: Although medication adherence and health-related quality of life (HRQL) are two different outcome measures, it is believed that adherence to medication leads to an improvement in overall HRQoL. The study aimed to evaluate the association between medication adherence and HRQoL.

Methods: A questionnaire-based cross-sectional study design was undertaken with hypertension patients attending public hospitals in Quetta city, Pakistan. HRQoL was measured by Euroqol EQ-5D. Medication adherence was assessed by the Drug Attitude Inventory. Descriptive statistics was used to tabulate demographic and diseaserelated information. Spearman's correlation was used to assess the association between the study variables. All analysis was performed using SPSS 17.0.

Results: Among 385 study patients, the mean age (SD) was 39.02 (6.59), with 68.8\% of males dominating the entire cohort. The mean (SD) duration of hypertension was $3.01 \pm 0.939$ years. Forty percent $(n=154)$ had a bachelor's degree level of education with $34.8 \%(n=134)$ working in the private sector. A negative and weak correlation $(-0.77)$ between medication adherence and EQ-5D was reported. In addition, a negative weak correlation ( -0.120$)$ was observed among medication adherence and EQ-VAS.
\end{abstract}

Conclusions: Correlations among the study variables were negligible and negative. Hence, there is no "apparent" relationship between the variables.

Keywords: Medication adherence, Health related quality of life, Association, Hypertension

\section{Background}

The concepts of health-related quality of life (HRQoL) and medication adherence are frequently used in clinical research for assessing pharmaceutical care and treatment outcomes [1]. Adherence to drug treatment usually refers to the extent to which patients follow the instructions of their physician or other health care providers [2]. HRQoL is the assessment of physical, psychological and social dimensions of health that are influenced by an individual's experiences, beliefs, expectations and perceptions [3]. In a broader context, medication adherence is a transitional

\footnotetext{
* Correspondence: fahaduob@gmail.com

${ }^{1}$ Department of Pharmacy, University of Baluchistan, Quetta, Pakistan/PhD candidate, Discipline of Social \& Administrative Pharmacy, School of Pharmaceutical Sciences, Universiti Sains Malaysia, Minden 11800, Penang, Malaysia

Full list of author information is available at the end of the article
}

outcome variable while $\mathrm{HRQoL}$ is an ultimate outcome representing conclusions following a course of care [1]. This entails that a change in adherence is likely to occur first, which is subsequently followed by a change in HRQoL while assessing treatment or interventional outcomes [4]. Therefore, it can be predicted that patients who adhere to their treatment regimen should experience improvements in HRQoL and vice versa. Nevertheless, it is not wise to rule out other factors affecting medication adherence and HRQoL. For example, in the case of chronic diseases like diabetes or hypertension, adherence might be positively associated with side effects and perhaps lower HRQoL. On the contrary, for acute diseases, adherence to medication might be associated with a swift advancement in improving HRQoL. It is now known that in terms of quality of life, chronically ill individuals show 
lower quality of life and are less adherent to their medication $[5,6]$.

Within this context, hypertension is a chronic disease that requires lifelong treatment. The success of therapy is thereby affected by the impact of the drug regime on the patient's well-being $[7,8]$. Consequently, comprehensive assessment of therapy must include assessment of medication adherence and HRQoL along with the evaluation of traditional bio-physiological measures. Antihypertensive therapies should be compared for their efficacy in controlling blood pressure and also improving or at least maintaining HRQoL [9]. Regardless of the nature of studies relating HRQoL in hypertension, it is frequently reported that hypertensive patients have decreased HRQoL $[10,11]$. In the presence of evidence based guidelines [12,13], a challenge faced by the healthcare providers is that even in the "controlled state", hypertensive patients were reported to have decreased HRQoL [14].

In the current literature, few studies have attempted to measure the association between medication adherence and HRQoL. Moreover, results from such studies provide conflicting results [1,15-17]. This may be because of the variations in assessing HRQoL and medication adherence, as well as the study population being examined [18]. In addition, more or less, such studies are often produced and reported from developed nations. Considering the unavailability of information from developing countries, the association between medication adherence and HRQoL was examined. The aim of this study was to examine the relationship between adherence and HRQoL in a hypertensive population attending public hospitals in the city of Quetta, Pakistan.

\section{Methods \\ Study design}

The study was designed as a questionnaire-based crosssectional descriptive analysis.

\section{Settings}

Two tertiary care hospitals [Sandamen Provisional Hospital (SPH) and Bolan Medical Complex Hospital $(\mathrm{BMCH})]$ were approached for data collection. Both of the institutes are teaching hospitals and are generalised in nature, currently providing services to about $70 \%$ of the entire city.

\section{Ethical approval}

To date, there is no ethical requirement for non-clinical observational studies in Pakistan [19]. However, permission to conduct the study was taken from the medical superintendent of the respective institutes (EA/FS/1021-2). In addition, written consent was also taken from the patients prior to data collection. The patients were informed about the research initiatives, confidentiality of their responses and their right to withdraw from the study with no penalty or effects on their treatment. In addition, the study also received its approval from the "Post Graduate Research Evaluation Committee" at School of Pharmaceutical Sciences, Universiti Sains Malaysia.

\section{Participants and sampling criteria}

The National Health Survey conducted by Pakistan's Medical and Research Council reported that hypertension affected $18 \%$ of the adult population in Pakistan [20]. Therefore, a prevalence-based sample of 385 hypertensive patients was selected for this study [21]. As the study was conducted in two different hospitals, 193 hypertensive patients were selected from SPH and 192 from $\mathrm{BMCH}$.

Patients aged 18 years and above, with confirmed diagnosis of hypertension, using antihypertensive medications for the last six months and being familiar with the national language of Pakistan (Urdu), were included in the study. Patients aged below 18 and above 80 years, those with co-morbidities and mental impairments, as well as immigrants from other countries and pregnant ladies were excluded from the study. The study was conducted from July 2010 to September 2010.

\section{Study variables and data collection}

Hospital pharmacists stationed at the cardiac unit of the respective hospitals were approached and trained by the principal researcher for data collection. Demographic information of the study respondents was taken, as written consent was provided by the patients for the initiation of the study. The Drug Attitude Inventory (DAI-10) and EuroQol quality of life scale (EQ-5D) were used to assess medication adherence and HRQoL, respectively. DAI-10 was originally available in English and was translated into Urdu (official language of Pakistan) by an independent professional translator. The translation was reconfirmed by a professor stationed at an academy of languages. However, EQ-5D was provided by the developers in Urdu. Both of the research instruments were tested for reliability (Cronbach's $\alpha$ being 0.70 and 0.75 for DAI-10 and EQ-5D, respectively) and validity. As the originality and consistency of the two instruments were stabilised, the final versions were made available to the pharmacists. Data from the pre-test evaluation were not included in the final analysis.

\section{Assessment of medication adherence}

DAI-10 was originally constructed by Voruganti and Awad [22] comprising ten items with responses in yes or no and scores ranging from 10 to -10 . Patients with scores of 6 to 10 were reported as adherent, 0 to 5 as moderately adherent and those in the negative ranges as non-adherent [2]. 


\section{Assessment of HRQoL}

The EQ-5D is a generic HRQoL instrument developed by the EuroQoL group. It consists of five dimensions that are further divided into three levels of severity. It is a standardised instrument for use as a measure of health outcome and provides a simple descriptive profile and a single index value for health status that can be used in the clinical and economic evaluation of health care as well as population health surveys [23]. The EQ-5D descriptive profile consists of five dimensions (mobility, self-care, usual activities, pain/discomfort and anxiety/depression), each of which can take one of three responses. The responses record three levels of severity (no problems/some or moderate problems/extreme problems) within a particular EQ-5D dimension. The visual analogue scale (VAS) is the other portion of EQ-5D consisting of a 20-cm health thermometer with two distinct end points, the best imaginable health state (score of 100) and the worst imaginable health state (score of 0 ). This information can be used as a quantitative measure of health outcome as judged by the individual respondents.

\section{Statistical analysis}

Descriptive statistics were used to describe demographic and disease characteristics of the patients. Percentages and frequencies were used for the categorical variables, while means and standard deviations were calculated for the continuous variables. The characteristics of the whole sample, medication adherence scores and HRQoL were presented.

EQ-5D was scored using values derived from the UK general population survey reported in 1995 [24]. Medication adherence was calculated using the criteria originated by the developers [22,25]. Spearman's rank correlation test was used to measure the association between medication adherence and HRQoL. All analyses were performed using SPSS version 17.0 (SPSS Inc., Chicago, IL).

\section{Results}

Table 1 reflects the demographic characteristics and HRQoL scores among the study participants. Among the 385 study patients, the mean age (SD) was 39.02 (6.59) years, with $68.8 \%$ of males dominating the entire cohort. The mean (SD) duration of hypertension was $3.01 \pm 0.939$ years. Forty percent $(n=154)$ had a bachelor's degree level of education with $34.8 \% \quad(n=134)$ working in the private sector. Almost $41 \%(n=140)$ had a monthly income of more than 15000 Pakistan rupees (Pk Rs) [1 Pk Rs=0.01172 \$US] with 75.1\% ( $\mathrm{n}=289)$ having an urban residency.

The mean EQ-5D descriptive score was $0.46 \pm 0.28$ and EQ-VAS score was $63.97 \pm 6.6$. A total of 29 different EQ-5D health states were described by the patients (Table 2). The majority of the participants $(n=112,29.1 \%)$ reported their health status (21122) indicating no problem in the second and third domain, while moderate problem in the first, fourth and fifth domain (mobility "first", self-care "second", usual activities "third", pain/discomfort "fourth" and anxiety/depression being the "fifth" domain). There was not a single patient who stated no problem in all five domains as shown in Table 2. Interestingly, poor treatment adherence (-1.89) was reported in the most frequent reported heath status. Moreover, participants with best health status (11112) among the study cohort reported the worst treatment adherence $(-4.0)$.

\section{Adherence scores}

The responses of patients to the DAI-10 scale are provided in Table 3. DAI-10 test scores ranged between 10 and -10 with the overall mean score of $-1.74 \pm 2.154$ and median score of -2 . Out of the 385 patients, 249 $(64.7 \%)$ were categorised as poorly adherent and 136 (35.3\%) as moderately adherent to their therapies. No patient was considered to be adhering well to their medication. Poor adherence was apparent in responses to questions 9, 5 and 2 where correct answers constituted $4.9,15.6$ and $30.4 \%$, respectively. The correct answers were highest in response to questions 6 and 7, which were 93.0 and $76.9 \%$, respectively.

The Spearman's rank order correlation coefficient between total adherence and EQ-5D scores was -0.77 and total adherence and EQ-VAS scores -0.120 (Table 4). Therefore, the current study findings indicate an inverse association between the included study variables. No significant difference was observed between the current study variables.

\section{Discussion}

The results from the present study show a weak or negligible negative correlation between medication adherence and HRQoL. The participants were also reported with decreased HRQoL and poor treatment adherence to medications. Similar results were reported in a meta analysis where hypertension patients were reported with decreased HRQoL [10]. In another study among hypertensive patients, lower medication adherence was associated with poor HRQoL in a population based survey in Brazil [14].

With the exception of the negative association, the current study findings agree with those in the literature $[1,16,26,27]$. However, Carbello et al. concluded that certain HRQoL domains are closely related to medication adherence in an HIV population [28]. These findings were again supported by Takemura and colleagues, who concluded that better adherence is associated with better HRQoL in their study among asthmatic patients in Japan [29]. 
Table 1 Characteristics of survey respondents and description of HRQOL scores

\begin{tabular}{|c|c|c|c|c|c|}
\hline Description & $\mathrm{N}(\%)$ & $\begin{array}{l}\text { Mean } \\
\text { EQ-5D Score }\end{array}$ & $\begin{array}{l}\text { Std } \\
\text { Deviation }\end{array}$ & $\begin{array}{l}\text { Mean } \\
\text { EQ-VAS } \\
\text { Score }\end{array}$ & $\begin{array}{l}\text { Std } \\
\text { Deviation }\end{array}$ \\
\hline \multicolumn{6}{|l|}{ Age (39.02 \pm 6.596$)$} \\
\hline $18-27$ & $48(12.5)$ & 0.5913 & 0.18401 & 66.81 & 5.652 \\
\hline $28-37$ & $186(48.3)$ & 0.5007 & 0.25706 & 64.68 & 5.862 \\
\hline $38-47$ & $128(33.2)$ & 0.4104 & 0.31491 & 59.87 & 7.160 \\
\hline$>48$ & $23(6.0)$ & 0.2576 & 0.28444 & 63.97 & 6.621 \\
\hline \multicolumn{6}{|l|}{ Gender } \\
\hline Male & $265(68.8)$ & 0.4677 & 0.28194 & 64.03 & 6.466 \\
\hline Female & $120(31.2)$ & 0.4669 & 0.29107 & 63.84 & 6.978 \\
\hline \multicolumn{6}{|l|}{ Education } \\
\hline Illiterate & $9(2.3)$ & 0.2543 & 0.33554 & 59.44 & 6.521 \\
\hline Religious & $62(16.1)$ & 0.3005 & 0.34637 & 60.63 & 6.744 \\
\hline Primary & $7(1.8)$ & 0.5583 & 0.18048 & 63.57 & 2.992 \\
\hline Matric & $51(13.2)$ & 0.4371 & 0.28744 & 64.59 & 7.245 \\
\hline Intermediate & $51(13.2)$ & 0.5231 & 0.25906 & 65.06 & 5.774 \\
\hline $\mathrm{BA} / \mathrm{BSC}$ & $154(40.0)$ & 0.5293 & 0.23171 & 64.84 & 6.130 \\
\hline Masters & $51(13.2)$ & 0.4835 & 0.28105 & 64.59 & 7.119 \\
\hline \multicolumn{6}{|l|}{ Occupation } \\
\hline Jobless & $97(25.2)$ & 0.4337 & 0.29882 & 63.24 & 7.077 \\
\hline Government official & $78(20.3)$ & 0.4796 & 0.27688 & 64.44 & 7.011 \\
\hline Private Job & $134(34.8)$ & 0.5295 & 0.23761 & 65.16 & 5.503 \\
\hline Businessman & $76(19.7)$ & 0.3886 & 0.32602 & 62.36 & 7.080 \\
\hline \multicolumn{6}{|l|}{ Income } \\
\hline $\mathrm{Nil}$ & $97(25.2)$ & 0.4337 & 0.29882 & 63.24 & 7.077 \\
\hline$<$ Pk Rs 5000 & $2(0.5)$ & 0.4210 & 0.33234 & 65.00 & 7.071 \\
\hline $5000-10000$ & $22(5.7)$ & 0.5628 & 0.19853 & 65.68 & 6.549 \\
\hline $10000-15000$ & $104(27.0)$ & 0.5231 & 0.23856 & 65.25 & 5.841 \\
\hline$>15000$ & $160(41.6)$ & 0.4392 & 0.30643 & 63.34 & 6.735 \\
\hline \multicolumn{6}{|l|}{ Locality } \\
\hline Urban & $289(75.1)$ & 0.5113 & 0.25466 & 64.97 & 6.156 \\
\hline Rural & $96(24.9)$ & 0.3356 & 0.32713 & 60.98 & 7.089 \\
\hline \multicolumn{6}{|c|}{ Duration of disease $(3.01 \pm 0.939)$} \\
\hline Less than 1 year & $26(6.8)$ & 0.5885 & 0.18203 & 67.04 & 4.976 \\
\hline $1-3$ years & 89 (23.1) & 0.5158 & 0.25582 & 65.33 & 6.335 \\
\hline $3-5$ years & $124(32.2)$ & 0.4738 & 0.26777 & 64.35 & 6.106 \\
\hline$>5$ years & $146(37.9)$ & 0.4110 & 0.31733 & 62.28 & 7.074 \\
\hline Total Sample & 385 & 0.4674 & 0.28444 & 63.97 & 6.621 \\
\hline
\end{tabular}

The negative association between medication adherence and HRQoL is explainable using the theoretical model of Self-Regulation [30]. Interest and involvement of patients in improving one's own health is the key determinant of a successful medical treatment. Medication adherence is an important component of disease state management; however, it is one phase of the entire process. HRQoL, on the other hand, encircles a complex web of psychosocial characteristics that can impact a patient's ability to manage their chronic disease and does not depend on a single factor. In the majority of cases, the patient observes their own behaviour and evaluates how this behaviour affects their current health status. Only if the desired results are not realised, a change in personal behaviour is initiated. If the patients are satisfied with the outcomes, they maintain status quo. A 
Table 2 Frequency of self-reported (EQ-5D) Health States

\begin{tabular}{|c|c|c|}
\hline EQ-5D Health Status & $\mathrm{N}$ & $\%$ Total \\
\hline 11112 & 1 & 0.3 \\
\hline 11122 & 21 & 5.5 \\
\hline 11123 & 4 & 1.0 \\
\hline 11222 & 39 & 10.1 \\
\hline 11223 & 8 & 2.1 \\
\hline 11232 & 2 & 0.5 \\
\hline 11233 & 1 & 0.3 \\
\hline 12122 & 12 & 3.1 \\
\hline 12222 & 6 & 1.6 \\
\hline 21112 & 6 & 1.6 \\
\hline 21121 & 1 & 0.3 \\
\hline 21122 & 112 & 29.1 \\
\hline 21123 & 12 & 3.1 \\
\hline 21132 & 8 & 2.1 \\
\hline 21212 & 1 & 0.3 \\
\hline 21222 & 37 & 9.6 \\
\hline 21223 & 13 & 3.4 \\
\hline 21232 & 18 & 4.7 \\
\hline 21233 & 9 & 2.3 \\
\hline 22122 & 11 & 2.9 \\
\hline 22123 & 5 & 1.3 \\
\hline 22212 & 1 & 0.3 \\
\hline 22222 & 17 & 4.4 \\
\hline 22223 & 8 & 2.1 \\
\hline 22231 & 1 & 0.3 \\
\hline 22232 & 11 & 2.9 \\
\hline 22233 & 18 & 4.7 \\
\hline 22322 & 1 & 0.3 \\
\hline 22323 & 1 & 0.3 \\
\hline Total & 385 & 100 \\
\hline \multicolumn{3}{|c|}{$\begin{array}{l}\text { Within } 29 \text { different health states, majority }(n=112,29.1 \%) \text { stated moderate } \\
\text { difficulty in the first, fourth mad fifth domain respectively, where as they stated } \\
\text { no difficulty in the second and third domain*. } \\
\text { *[(Mobility, self-care, usual activities, pain/discomfort and anxiety/depression) } \\
\text { Domains of HRQoL in order]. }\end{array}$} \\
\hline
\end{tabular}

weak association from the current study is in line with the recognition that HRQoL is affected by a number of factors and is not limited to medication adherence only.

A possible explanation of this negative association can be attributed to the measurement of medication adherence and HRQoL. Although there is no "gold standard" for adherence and HRQoL measurement [31,32], it is always advisable to use a disease/population specific instrument. This can result in a response to small changes in medication adherence and HRQoL and perhaps can give a stronger association. Even though Cote et al. used four different instruments of HRQoL assessment (RAND-12, SF-12, HUI-2 and HUI-3) and the Morisky
Table 3 Drug Adherence Data

\begin{tabular}{|c|c|c|}
\hline Drug adherence item & $\begin{array}{c}\text { True } \\
(\%)\end{array}$ & $\begin{array}{c}\text { False } \\
(\%)\end{array}$ \\
\hline $\begin{array}{l}\text { For me, the good things about } \\
\text { medication outweigh the bad. }\end{array}$ & 58.4 & 41.6 \\
\hline I feel uncomfortable on medication. & 69.6 & 30.4 \\
\hline I take medications of my own choice. & 40.3 & 59.7 \\
\hline Medications make me feel more relaxed. & 60.3 & 39.7 \\
\hline Medication makes me feel tired and sluggish. & 84.4 & 15.6 \\
\hline I take medication only when I am sick. & 93.0 & 7.0 \\
\hline I feel more normal on medication. & 76.9 & 23.1 \\
\hline $\begin{array}{l}\text { It is unnatural for my mind and body to be } \\
\text { controlled by medications. }\end{array}$ & 40.0 & 60.0 \\
\hline My thoughts are clearer on medication. & 4.9 & 95.1 \\
\hline $\begin{array}{l}\text { By staying on medications, } \\
\text { I can prevent getting sick. }\end{array}$ & 60.0 & 40.0 \\
\hline My thoughts are clearer on medication. & 4.9 & 95.1 \\
\hline $\begin{array}{l}\text { By staying on medications, } \\
\text { L can prevent getting sick. }\end{array}$ & 60.0 & 40.0 \\
\hline
\end{tabular}

Medication Adherence Scale (MMAS) for assessing medication adherence, proposed a disease-specific instrument, which is in line with our suggestions [1].

The negative association that was observed here may be linked to the frequency and class of antihypertensive medication used by the patients. The efficacy of antihypertensive agents is unquestionable but certain side effects are always associated with the therapy [33,34]. Side effects in "adherents" can be one possible reason for the decreased HRQoL. Moreover, different antihypertensive agents affect HRQoL in a different way. Even medications from the same pharmacological class, with the same efficacy and safety profile, show different impact on HRQoL [7]. For example, a study involving two different calcium channel blockers, nifedipine and amlodipine, concluded that nifedipine had a positive effect on overall quality of life compared with no change in the amlodipine group [35].

In this context, the duration of the disease itself is very important in interpreting the association between medication adherence and HRQoL. Patients who are recently diagnosed with hypertension may experience an increased HRQoL for the first few months of therapy. However, for chronic hypertensive patients, adherence to

Table 4 Correlation coefficient (Total adherence score and EQ-VAS score)

Spearman's Rho Adherence score EQ-VAS score EQ-5D Score

\begin{tabular}{lccc}
\hline Correlation Coefficient & 1.000 & -0.120 & -0.77 \\
\hline Sig. (2-tailed)* & - & 0.169 & 0.132 \\
\hline $\mathrm{N}$ & 385 & 385 & 385 \\
${ }^{*}$ Correlation significant at the 0.05 level. & &
\end{tabular}


medication might not improve HRQoL. Subsequently, HRQoL in chronic patients can be observed as "maintained" but this preservation is never taken as "improved" by the patients. This is supported by the current study results, where 146 (37.9\%) and 124 (32.3\%) of the respondents had hypertension for more than five years and within three to five years, respectively, and reported decreased HRQoL.

The current findings revealed that the study cohort was dominated by age group of 28-37 years (48.3\%) and patients with bachelor's level of education (40.0\%). However, both treatment adherence and HRQoL are multifactor phenomenon and success or failure of therapy and overall health status are not dependent on a single factor $[2,3]$. Factors such as gender, low socioeconomic status, prescribed drugs, posology, lack of social support, poor patient provider relationship, cost, forgetfulness, and presence of psychological problems should also be kept in mind and evaluated before coming to a conclusion regarding treatment adherence and its effect on HRQoL.

\section{Conclusion}

In general, the weak correlation between medication adherence and HRQoL reflects no "apparent" relationship. The absence of an association indicates other factors affecting HRQoL during the course of care. Further investigations of the relationship between medication adherence and HRQoL using disease-specific instruments are warranted.

\section{Limitations}

This study has some limitations. Patients with comorbidities were excluded from the study as the current study was conducted at a remote place with no available database. Co-morbidities, however, can modify adherence behaviour in patients as well as HRQoL. In addition, adherence was assessed by selfreported method. The use of other tools like pill counts or electronic monitoring can give sensitive results, but it is not possible to employ such methods at present as the area lacks basic infrastructure. In addition, the results were drawn from one city and cannot be generalised to the entire country.

\section{Competing interests}

There is no conflict of interest. No funding was received for this study.

\section{Author details}

'Department of Pharmacy, University of Baluchistan, Quetta, Pakistan/PhD candidate, Discipline of Social \& Administrative Pharmacy, School of Pharmaceutical Sciences, Universiti Sains Malaysia, Minden 11800, Penang, Malaysia. ${ }^{2}$ Discipline of Social \& Administrative Pharmacy, School of Pharmaceutical Sciences, Universiti Sains Malaysia, Minden 11800, Penang Malaysia. ${ }^{3}$ Humber River Regional Hospital, 2175 Keele Street, Suite 243A, Toronto Ontario M6M 3Z4, Canada. ${ }^{4}$ School of Pharmacy, Allianze University, College of Medical Sciences, Kepala Batas 13200, Penang, Malaysia. ${ }^{5}$ College of Pharmacy, King Saud University, Riyadh 11451, Saudi Arabia. ${ }^{6}$ Faculty of
Pharmacy, Universiti Teknologi MARA (UiTM), Bertam 13200, Penang , Malaysia.

\section{Author's contribution}

FS and NUH conducted the survey and drafted the initial manuscript. MAH, AAS and AAG designed and supervised the study. MA, HA and MF helped in statistical analysis, interpretation and manuscript revision. All authors read and approved the final manuscript.

Received: 31 December 2011 Accepted: 30 April 2012

Published: 30 April 2012

\section{References}

1. Côté I, Farris K, Feeny D: Is adherence to drug treatment correlated with health-related quality of life? Qual of Life Res 2003, 12:621-633.

2. Saleem F, Hassali MA, Shafie AA, Awad AG, Bashir S: Association between Knowledge and Drug Adherence in Patients with Hypertension in Quetta, Pakistan. Trop J Pharm Res 2011, 10:125-132.

3. Saleem F, Hassali MA, Shafie AA: A cross-sectional assessment of healthrelated quality of life (HRQoL) among hypertensive patients in Pakistan Health Expectations 2012. doi:10.1111/j.1369-7625.2012.00765.x.

4. Green LW, Kreuter MW: Health program planning: An educational and ecological approach. 2nd edition. McGraw-Hill Companies; 2005.

5. Bonomi AE, Patrick DL, Bushnell DM, Martin M: Validation of the United States' version of the World Health Organization Quality of Life (WHOQOL) instrument. J Clin Epidemio/ 2000, 53:1-12.

6. Martínez Y, Prado-Aguilar C, Rascón-Pacheco R, Valdivia-Martínez J: Quality of life associated with treatment adherence in patients with type 2 diabetes: a cross-sectional study. BMC Heal Serv Res 2008, 8:164.

7. Nunes Ml: The relationship between quality of life and adherence to treatment. Curr Hypertens Reports 2001, 3:462-465.

8. Os I: Quality of life in hypertension. J Hum Hypertens 1994, 8:S27-S30.

9. Leonetti G, Comerio G, Cuspidi C: Evaluating quality of life in hypertensive patients. J CardiovasC Pharmacol 1994, 23:S54-S58.

10. Trevisol DJ, Moreira LB, Kerkhoff A, Fuchs SC, Fuchs FD: Health-related quality of life and hypertension: a systematic review and meta-analysis of observational studies. J Hypertens 2011, 29:179-88.

11. Korhonen PE, Kivelä SL, Kautiainen H, Järvenpää S, Kantola I: Health-related quality of life and awareness of hypertension. J Hypertens 2011, 29:2070-2074.

12. Godley P, Pham H, Rohack J, Woodward B, Yokoyama K, Maue SK: Opportunities for improving the quality of hypertension care in a managed care setting. Am J Health Syst Pharm 2001, 58:1728-1733.

13. Whitworth J: 2003 World Health Organization (WHO)/International Society of Hypertension (ISH) statement on management of hypertension. J Hypertens 2003, 21:1983-1992.

14. Trevisol D, Moreira L, Fuchs F, Fuchs S: Health-related quality of life is worse in individuals with hypertension under drug treatment: results of populationbased study. Journal of Human Hypertension 2011. doi:10.1038/jhh.2011.48.

15. Holt EW, Muntner P, Joyce CJ, Webber L, Krousel-Wood MA: Health-related quality of life and antihypertensive medication adherence among older adults. Age and Ageing 2010, 39:481-487.

16. Pippalla $R$, Chinburapa $V$, Duval $R$, Akula R: Interrelationships of quality of life, compliance, clinical outcomes and life satisfaction: a cross-sectional study on hypertensive geriatrics. J Clin Pharm Ther 1997, 22:357-369.

17. Trivedi RB, Ayotte B, Edelman D, Bosworth HB: The association of emotional well-being and marital status with treatment adherence among patients with hypertension. J Behav Med 2008, 31:489-497.

18. Coyne KS, Davis D, French F, Hill MN: Health-related quality of life in patients treated for hypertension: a review of the literature from 1990 to 2000. Clin Ther 2002, 24:142-169.

19. National Bioethics Committee Pakistan: Ethical Research Committee-Guidelines 2011. [http://www.pmrc.org.pk/erc_guidelines.htm]

20. National Health Survey of Pakistan 1990-1994: Research activites 2011 [http://www.pmrc.org.pk/researchactivities.htm].

21. Daniel WW: Biostatistics: basic concepts and methodology for the health sciences. New York: John Wiley \& Sons; 2010.

22. Voruganti L, Awad A: Neuroleptic dysphoria: towards a new synthesis. Psychopharmacology 2004, 171:121-132.

23. Williams A: EuroQol-a new facility for the measurement of health-related quality of life. Health Policy 1990, 16:199-208. 
24. Dolan P, University of York. Centre for Health Economics: A social tariff for EuroQol: results from a UK general population survey. The University of York: Center for Health Economics; 1995.

25. Kim JH, Kim SY, Ahn YM, Kim YS: Subjective response to clozapine and risperidone treatment in outpatients with schizophrenia. Progress in Neuro-Psychopharmacology and Bioll Psychiatry 2006, 30:301-305.

26. Billups SJ, Malone DC, Carter BL: The relationship between drug therapy noncompliance and patient characteristics, health-related quality of life, and health care costs. Pharmacotherapy 2000, 20:941-949.

27. Sung J, Nichol MB, Venturini F, Bailey KL, McCombs JS, Cody M: Factors affecting patient compliance with antihyperlipidemic medications in an HMO population. Am J Managed Care 1998, 4:1421-1430

28. Carballo E, Cadarso-Suárez C, Carrera I, Fraga J, De la Fuente J, Ocampo A, Ojea R, Prieto A: Assessing relationships between health-related quality of life and adherence to antiretroviral therapy. Qual Life Res 2004, 13:587-599.

29. Takemura M, Kobayashi M, Kimura K, Mitsui K, Masui H, Koyama M, Itotani R, Ishitoko M, Suzuki S, Aihara K: Repeated instruction on inhalation technique improves adherence to the therapeutic regimen in asthma. J Asthma 2010, 47:202-208.

30. Bandura A: The Primacy of Self-Regulation in Health Promotion. Appl Psychol 2005, 54:245-254.

31. Osterberg L, Blaschke T: Adherence to medication. N Engl J Med 2005, 353:487-497.

32. Saarni Sl, Härkänen $T$, Sintonen $H$, Suvisaari J, Koskinen $S$, Aromaa A, Lönnqvist J: The impact of 29 chronic conditions on health-related quality of life: a general population survey in Finland using 15D and EQ-5D. Qual Life Res 2006, 15:1403-1414.

33. Croog SH, Levine S, Testa MA, Brown B, Bulpitt CJ, Jenkins CD, Klerman GL, Williams GH: The effects of antihypertensive therapy on the quality of life. N Engl J Med 1986, 314:1657-1664.

34. Jacob S, Rett K, Henriksen EJ: Antihypertensive therapy and insulin sensitivity: Do we have to redefine the role of $\beta$-blocking agents? Am J Hypertens 1998, 11:1258-1265.

35. Testa MA, Anderson RB, Nackley JF, Hollenberg NK: Quality of life and antihypertensive therapy in men-a comparison of captopril with enalapril. N Engl J Med 1993, 328:907-913.

doi:10.1186/1471-2458-12-318

Cite this article as: Saleem et al:: Does treatment adherence correlates with health related quality of life? findings from a cross sectional study. BMC Public Health 2012 12:318.

\section{Submit your next manuscript to BioMed Central and take full advantage of:}

- Convenient online submission

- Thorough peer review

- No space constraints or color figure charges

- Immediate publication on acceptance

- Inclusion in PubMed, CAS, Scopus and Google Scholar

- Research which is freely available for redistribution 